\title{
THE EFFECTS OF POWER PLANT PASSAGE ON ZOOPLANKTON MORTALITIES: EIGHT YEARS OF STUDY AT THE DONALD C. COOK NUCLEAR PLANT
}

\author{
Marlene S. Evans, Glenn J. Warren and Donna I. Page \\ Great Lakes Research Division, The University of Michigan, Ann Arbor, MI 48109, U.S.A.
}

(Received December 1984)

\begin{abstract}
Alsstract-Zooplankton mortalities resulting from passage through the Donald C. Cook Nuclear Plant (southeastern Lake Michigan) were studied over an 8-year (1975-1982) period. The power plant operated at a low $\Delta T\left(<12^{\circ} \mathrm{C}\right)$ and discharge water temperatures did not exceed $35^{\circ} \mathrm{C}$ (except September 1978). While zooplankton mortalities were significantly greater in discharge than intake waters, differences were small, averaging $<3 \%$. There was no evidence of additional delayed effects on zooplankton mortality following plant passage. Calanoid copepods (Diaptomus spp, Eurytemora affinis and Limnocalanus macrurus) were most sensitive to plant passage, cyclopoid copepods least sensitive, while cladocerans (Daphnia spp, Eubosmina coregoni) were intermediate in sensitivity. There was no relationship between zooplankton mortalities and temperature $(\Delta T$, discharge water temperature), suggesting that thermal stresses were not the major source of mortality. The single exception was September 1978 when discharge water temperatures exceeded $35^{\circ} \mathrm{C}$ and there were large differences between intake and discharge water zooplankton mortalities (net mortality differences of $14-22 \%$ for the two units). Mechanical stresses appeared to be the major cause of zooplankton mortality. However, there was only a weak relationship between mortality as a result of plant passage and zooplankton size. Based on our long-term preoperational (1970-1974) and operational (1975-1982) ecological studies in the vicinity of the power plant, we hypothesize that fish predation, rather than power plant operation, probably was the major source of zooplankton mortality in inshore waters during much of the year.
\end{abstract}

Key words -zooplankton mortalities, thermal effects, power plants

\section{INTRODUCTION}

Power plants, by withdrawing water from a lake, river or sea for use in their condenser cooling systems, stress entrained organisms. Such stresses include rapid thermal elevation, mechanical damage and exposure to biocides. In the United States, as the number and size of power plants increased, concern regarding the environmental effects of plant operation grew. Consequently, plants were subjected to more rigorous licensing requirements. One of these, 316(b) of the Federal Water Pollution Control Act, requires application of "the best technology available to cooling water intake structures so that location, design, construction, and capacity of such structures will minimize adverse environmental impacts". In order to meet this licensing requirement, power plants were required to conduct monitoring studies to quantify the extent to which their operation harmed indigenous biota.

The Donald C. Cook Nuclear Plant (Bridgman, Mich.) is a two-unit power plant which, at full operational capacity, produces $2200 \mathrm{MW}$ (e). The plant is one of the largest of nearly 30 nuclear and coal-fired plants on Lake Michigan. At full operational capacity, the Donald C. Cook Nuclear Plant draws approx. $6300 \mathrm{~m}^{3}$ of lake water each minute through its once-through cooling system. Water is drawn into the plant from two subsurface intakes located at approx. the 9-m depth contour, heated and returned to the lake $10 \mathrm{~min}$ later through three subsurface discharge jets located at approx. the 6-m depth contour. As a consequence of its size and use of very large volumes of cooling water, monitoring studies conducted at this plant were especially detailed.

Zooplankton mortality studies extended over an 8-year period while lake surveys were conducted over a more extensive preoperational (1970-1974) and operational (1975-1982) period. These monitoring studies were designed to investigate whether plant operation had a significant effect on zooplankton which passed through the condenser cooling systems and on zooplankton in the inshore region. Mortality effects as a result of plant passage were considered by season and over the long-term (8 years) for the various zooplankton taxa observed in the cooling waters. Here we summarize the results of these 8 years of mortality investigations. More detailed presentations of these data and other aspects of the zooplankton monitoring program appear in Evans (1975) and Evans et al. $(1978,1982,1986)$.

\section{MATERIALS AND METHODS}

Zooplankton mortality studies were conducted once a month, 12 months a year from February 1975 to May 1982. 


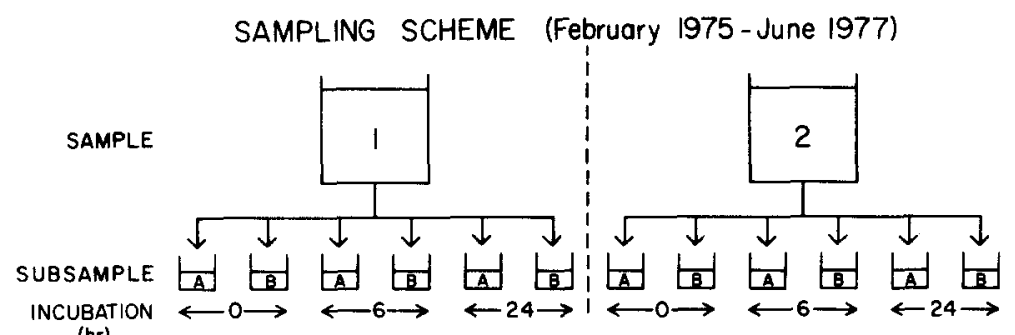

(hr)

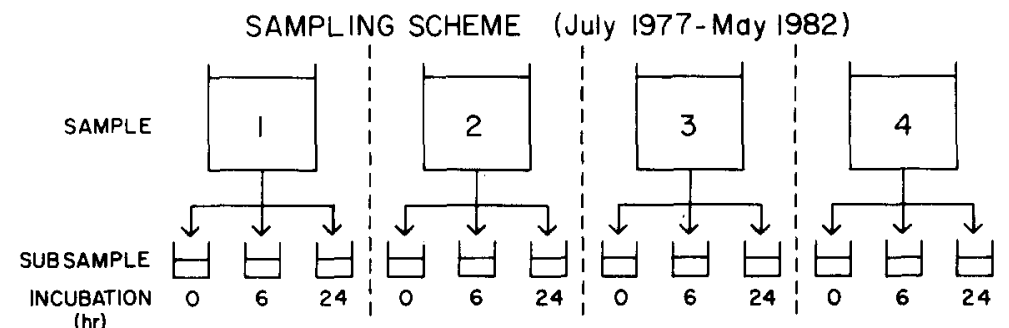

Fig. 1. Schematic of the sampling and subsampling scheme used to determine zooplankton mortality at a given location during February 1975-June 1977 (upper panel) and July 1977-1982 (lower panel).

Unit 1 went into production in February 1975 while Unit 2 went into production in April 1978. Each unit was shut down periodically for refueling. Studies were conducted only at operational units.

Samples were collected from the intake and discharge forebays with the Zaggot Trap sampler and a Hale diaphragm pump (Yocum et al., 1978). Sampling was conducted for $2 \mathrm{~min}$ with approx. $0.2 \mathrm{~m}^{2} \mathrm{~min}^{-1}$ of water filtered through the $156-\mu \mathrm{m}$ mesh netting. Water temperature was measured at the time of sample collection. Immediately after collection, the filter carrier was washed down with water from the intake forebay. For discharge water samples, this rapid cooling mimicked the thermal regime plant-passed zooplankton would have experienced upon return to the lake.

Prior to July 1977, two samples were collected from each intake and discharge location. In an on-site laboratory, each was divided (Fig. 1) as many times as necessary in a Folsom plankton splitter to give six subsamples (a total 12 subsamples from the original two samples), each containing several hundred organisms. Each subsample was placed in a 1-1. beaker containing approx. $500 \mathrm{ml}$ of filtered $(156-\mu \mathrm{m})$ intake water, and maintained in the dark at ambient lake water temperatures in an incubator until examination. Four subsamples (two from each original sample) were immediately examined $(0 \mathrm{~h})$. The remaining eight subsamples were used to investigate delayed mortality effects. Four subsamples were examined $6 \mathrm{~h}$ later and the remaining four examined $24 \mathrm{~h}$ later. As only two replicate samples were collected per location and incubation time, statistical analyses were limited to investigating intake-discharge mortality differences across large data sets, i.e. analyses for mortality differences across several months of study (Evans et al., 1978).

Beginning in July 1977 , we improved the statistical design of these mortality studies (Fig. 1). Four (rather than two) samples were collected from each intake and discharge location. However, only three subsamples $(0,6$ and $24-h)$ were obtained from each sample, resulting in the same number of subsamples being examined for each location (12). Although this change in sampling design did not alter the effort required to examine subsamples, the design change did allow more efficient statistical examination of the data including analyses, by month, of differences in intake and discharge mortalities.

In the laboratory, each subsample was examined in a circular counting dish under a stereozoom dissecting micro- scope. Organisms which exhibited no visceral or appendicular movements, even after gentle prodding, were classified as "dead". At the beginning of the mortality studies, we investigated the feasibility of using vital stains: however, none of the stains tested proved as reliable as using the visual observation method (Evans, 1975). Organisms were identified to suborder (nauplii), genus (Asplanchna spp, immature copepodites), or species (adult copepods, cladocerans). After identification and enumeration, dead animals were placed in a separate vial and preserved with a sugar-formalin solution (Haney and Hall, 1973). After complete examination of the subsample, remaining live zooplankton were preserved for later examination and identification.

For each sample and incubation period, the percentage (weighted mean) of dead zooplankton was calculated. Time series plots of these data allowed us to investigate whether or not mortalities varied seasonally or with differences in the mode of plant operation (pumping rate, absolute thermal elevation, discharge water temperature). We also calculated mean zooplankton mortalities for intake and discharge collections over the 8 years of study. These values also were based on weighted means. Use of a weighted mean [total number of dead animals in the various subsamples (or samples) divided by the total number of live and dead animals in the various subsamples (or samples)] corresponds to the use of a ratio estimator (Raj, 1968; Cochran, 1977) Weighted mean mortalities are preferred to simple means because samples and subsamples were composed of unequal numbers of zooplankton which were exposed, as groups, to the stresses of collection and laboratory handling.

Prior to July 1977, when only two samples were collected per location for a given sampling date (Fig. 1), it was not possible to statistically compare intake and discharge mortalities by collection date and incubation period. Beginning in July 1977, when the statistical design of the sample collection program was improved (i.e. four rather than two samples were collected from each location for each time, Fig. 1), such analyses could be conducted. Since the sample size was small $(n=4)$ and the data did not meet the assumptions of normality, the Smirnov upper-sided twosample test, a nonparametric test, was used. The test compares the distribution functions associated with two populations, $F(x)$ or intake mortality and $G(x)$ or discharge mortality. The assumptions are that the samples are randomly collected from the two populations, that they are mutually independent, and that the measurement scale is at 
least ordinal. The test hypothesis is that $F(x) \leqslant G(x)$, i.e. intake mortalities tend to be smaller than discharge mortalities. The alternate hypothesis is that $F(x)>G(x)$ (Conover, 1980). Analyses were conducted only for those zooplankton taxa which were abundant in the four replicate samples. Nauplii, immature and adult Cyclops spp and Diaptomus spp, Bosmina longirostris, Eubosmina coregoni and Daphnia spp met this criterion during at least one season (e.g. summer) of the year.

The upper-sided Wilcoxon signed rank test, another nonparametric test, was used to investigate differences in zooplankton mortality (by taxa and incubation period) over the 8 years (1975-1982) of study. The data consisted on $n^{\prime}$ observations $\left(x_{1}, y_{1}\right), \ldots,\left(x_{n^{\prime}}, y_{n^{\prime}}\right)$ of the respective random variates $\left(X_{1}, Y_{1}\right), \ldots,\left(X_{n^{\prime}}, Y_{n^{\prime}}\right)$, i.e. mean intake and discharge mortalities for the given sampling dates, locations, and incubation periods. The absolute difference $\left|D_{i}\right|=\left|Y_{i}-X_{i}\right|$ is computed for each pair of observations. The test hypothesis is that the $X_{i}$ 's tend to be equal to or smaller than the $Y_{i}$ 's while the alternate hypothesis is that the $X_{i}^{\prime}$ 's tend to be larger than the $Y_{i}^{\prime}$ 's. The assumptions of the test are that the distribution of each $D_{i}$ is symmetric, the $D_{i}$ 's are mutually independent, the $D_{i}$ 's all have the same median, and that the measurement scale of the $D_{i}$ 's is at least interval (Conover, 1980).

\section{RESULTS}

Since our study was conducted over 8 years, the data sets are extensive. As it is neither practical nor necessary to present the complete data sets, our graphic presentations of the seasonal aspects of zooplankton mortality are limited to the 1977-1978 data sets. These data are broadly representative of the larger data sets. Detailed presentations of the full data sets (graphs, tables, etc.) appear in the various reports by Evans (see the introduction).

Intake water temperatures (Fig. 2) varied seasonally, from $<1^{\circ} \mathrm{C}$ to $>24^{\circ} \mathrm{C}$. Although intake temperature seasonal cycles were similar between years, some differences did occur. For example, an upwelling occurred during the July 1978 mortality study but not during the July 1977 study. Intake water temperatures were warmer in August and September 1978 than a year earlier.

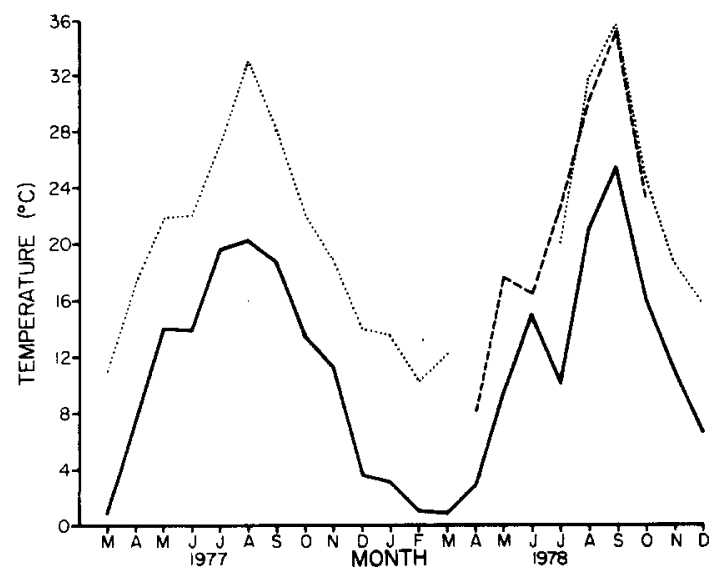

Fig. 2. Intake and discharge water temperatures $\left({ }^{\circ} \mathrm{C}\right)$ for Unit 1 and Unit 2, 1977-1978. Unit 2 began operation in April 1978 and both units occasionally were shutdown during the study. Intake; $\cdots .$. discharge No. $1 ; \ldots$ discharge No. 2.
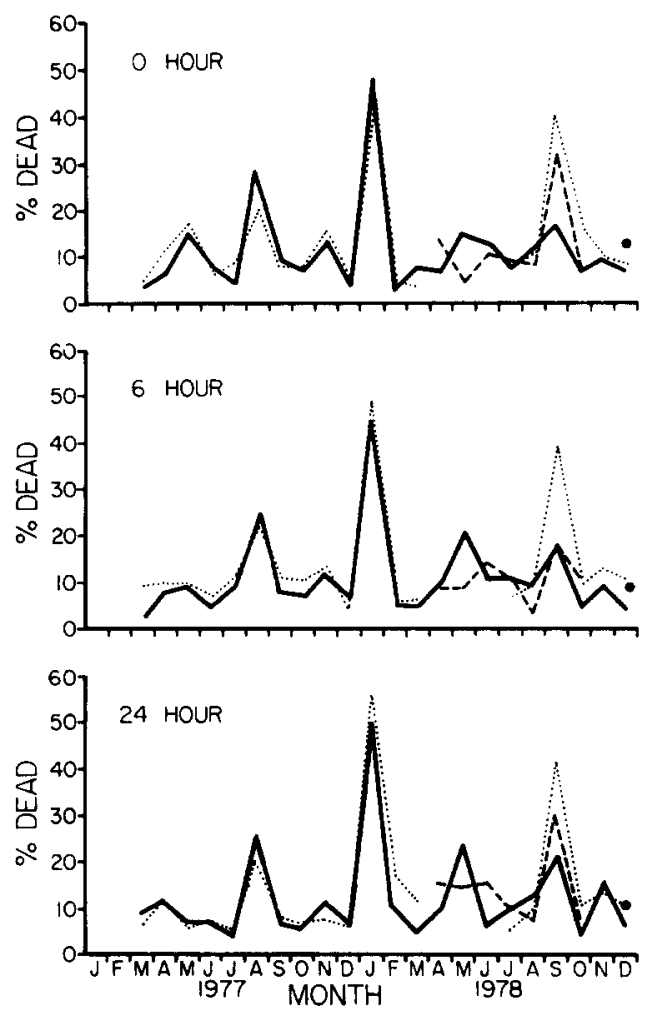

Fig. 3. Monthly mean mortality (\%) for total zooplankton at each incubation time. A large circle represents the discharge 2 value for December 1978. — Intake; ..... discharge No. 1; --.-. discharge No. 2.

Discharge temperatures (Fig. 2) generally were $<12^{\circ} \mathrm{C}$ higher than intake temperatures, varying seasonally with intake temperatures. In summer, temperatures approached but generally did not exceed $35^{\circ} \mathrm{C}$. The single exception over the eight years of study occurred in September 1978 when intake waters were unusually warm, averaging $26.7^{\circ} \mathrm{C}$. Although intake waters were heated by $<9^{\circ} \mathrm{C}$, discharge water temperatures were high averaging $35.6^{\circ} \mathrm{C}$ for Unit 1 and $35.2^{\circ} \mathrm{C}$ for Unit 2 . Over the 8-year study period, the $\Delta T$ for Unit 1 averaged $9.9^{\circ} \mathrm{C}$ while the $\Delta T$ for Unit 2 averaged $6.9^{\circ} \mathrm{C}$. Unit 1 pumped at a rate varying from 2090 to $3230 \mathrm{~m}^{3} \mathrm{~min}^{-1}$ and averaged $2964 \mathrm{~m}^{3} \mathrm{~min}^{-1}$ : Unit 2 pumped at a rate ranging from 3230 to $4484 \mathrm{~m}^{3} \mathrm{~min}^{-1}$ and averaged $3979 \mathrm{~m}^{3} \mathrm{~min}^{-1}$. Thus, Unit 2 operated at a higher pumping rate (approx. 34\%) but at a lower $\Delta T$ than Unit 1 .

Total zooplankton mortalities varied seasonally (Fig. 3). There were no obvious relationships between intake mortality and seasonality in water temperatures. In general, discharge mortalities followed intake mortality trends. Differences between intake and discharge mortalities generally were small, differing by only a few percent. The notable exception was September 1978, when 0-h intake mortalities averaged $17.5 \%$ whereas Unit 1 and Unit 2 discharge mortalities averaged 39.5 and $31.6 \%$ respectively. Overall, mortality differences did not increase in 

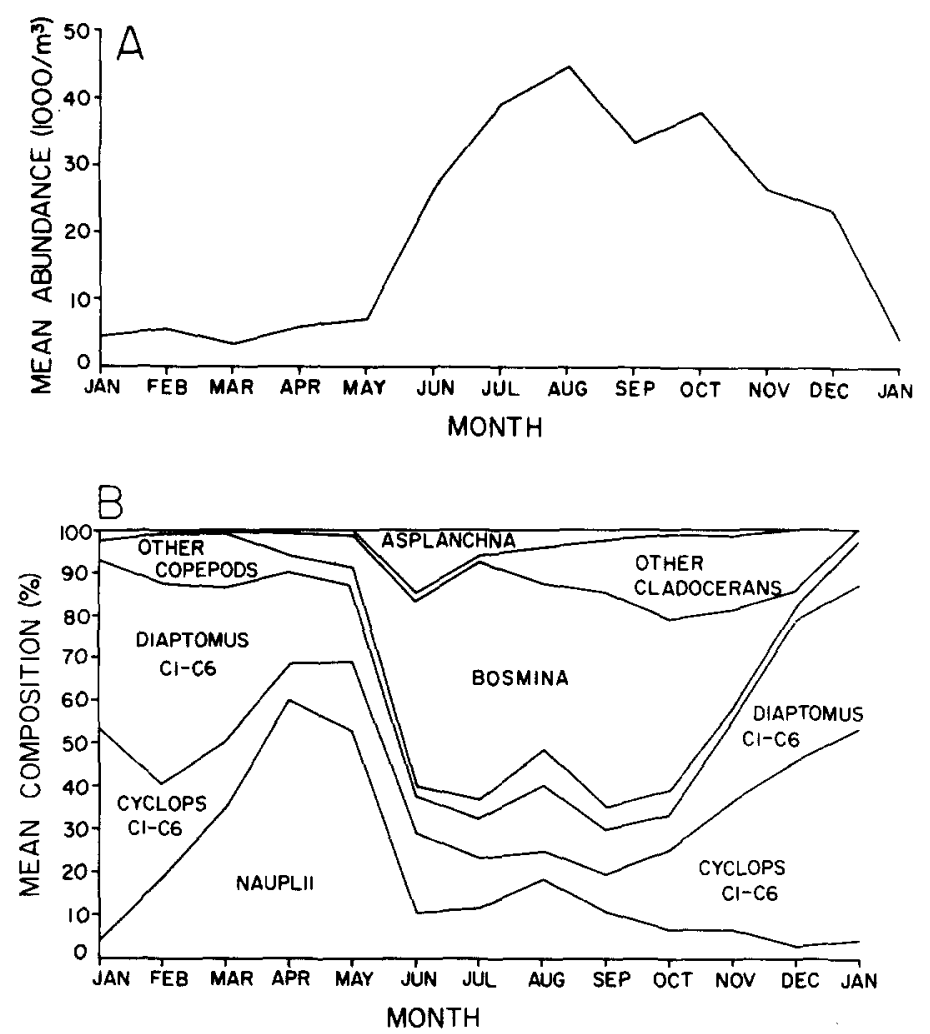

Fig. 4. Mean (A) abundance and (B) percent composition by month of zooplankton in the intake waters of the Donald C. Cook Nuclear Power Plant, 1975-1982.

summer when discharge water temperatures were higher.

Zooplankton exhibited strong seasonal variations in abundance and composition (Fig. 4). The overwintering zooplankton community was dominated by Cyclops spp (primarily immature) and Diaptomus spp (primarily adult) copepodites. Both genera were dominants during all months of the year. Conversely, other copepods were common only during winter and spring (Limnocalanus macrurus) and summer (Eurytemora affinis) but were never major components of the zooplankton, even during their period of maximum abundance. Nauplii were major components of the spring zooplankton community. Cladocerans increased in dominance through late spring with Bosmina longirostris the major taxon. Other numerically important cladocerans were Daphnia spp and Eubosmina coregoni.

During many months of the several-year study, at least one zooplankton taxon had significantly $(\alpha=0.05)$ higher mortalities in discharge than intake waters. However, there was not a consistent pattern between significant mortality differences and water temperature. This is illustrated by considering the representative 0-h data for the July 1977-December 1978 period (Table 1). In August 1978 for Unit 1, significant differences in mortalities between intake and discharge waters were detected for nauplii, $C y$ clops spp copepodites (immatures and adults), and immature Diaptomus spp copepodites. However, in
August 1977, differences were not statistically significant even though Unit 1 discharge water temperatures were similar between the two periods. In September 1978, differences were statistically significant for all taxa except Bosmina longirostris. In September 1977, when discharge water temperatures were lower, differences were statistically significant for Bosmina longirostris.

Intake mortalities for total zooplankton at 0 -h averaged $10.2 \%$ while mean mortalities in Unit 1 and Unit 2 discharge waters averaged 11.4 and $13.4 \%$ respectively (Table 2 ). For the $6-\mathrm{h}$ incubations, mean mortalities were $10.6,12.7$ and $11.0 \%$ respectively while, for the $24-\mathrm{h}$ incubations, these values were $12.0,14.5$ and $12.8 \%$ respectively (no summary tables are presented for the 6- and 24-h incubations but appear in Evans et al., 1986). Thus, there was no evidence of increased mortality of plant-passed zooplankton with time.

At the taxonomic level (Table 2), there was a weak trend for the larger zooplankton to have a greater mean difference between intake and discharge water mortalities than smaller zooplankton. Largest mean mortality differences were observed for the largest taxa, i.e. immature and adult Limnocalanus macrurus and Leptodora kindtii; adults of these species attain lengths of $2.3-3.2 \mathrm{~mm}$ and $18 \mathrm{~mm}$ respectively (Edmondson, 1959). Mean mortality differences also were large for Holopedium gibberum, a delicate cladoceran enclosed in a gelatinous sheath. However, the 
Table 1. Results of the Smirnov one-sided two-sample tests comparing discharge and intake 0-h sample mortalities for nine zooplankton taxa categories by month of collection. - Indicates insufficient data for the test, NS indicates discharge mortalities were not significantly $(P>0.05)$ higher than intake values, and *indicates discharge mortalities were significantly $(P<0.05)$ higher than intake values

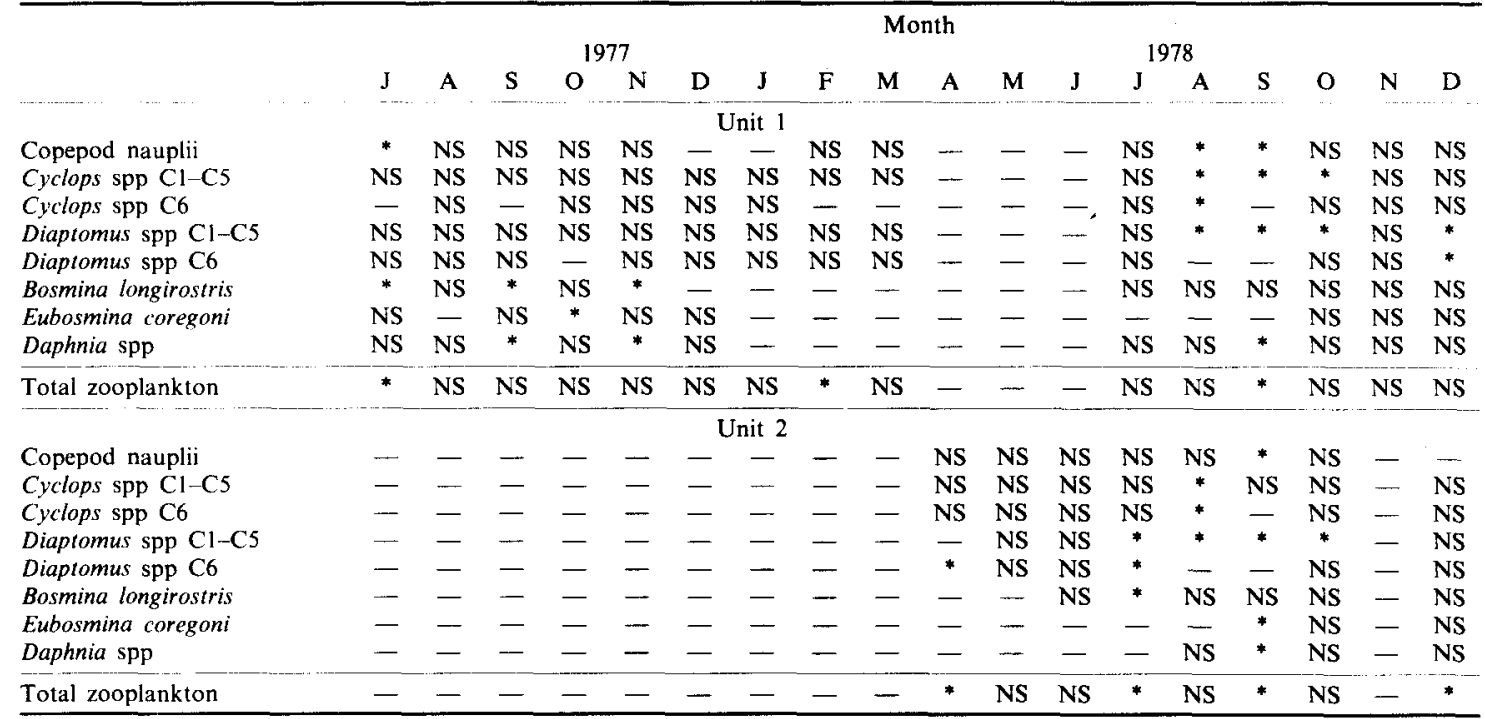

mortality-size relationship was not consistent for smaller ( $<2 \mathrm{~mm}$ ) zooplankton. This is best illustrated by considering the mean mortalities for the four Diaptomus species, i.e D. minutus, D. ashlandi, $D$. oregonensis and $D$. sicilis. These species differ substantially in size with reported maximum lengths of $0.5-1.0,0.9-1.4,1.3-1.5$ and $1.1-1.9 \mathrm{~mm}$, respectively (Edmondson, 1959). However, mean mortality difference for the four species did not increase with animal size.
Over the long-term ( 8 years), many taxa had significantly $(\alpha=0.05)$ higher mortalities in discharge waters than in intake waters (Table 3). For Unit 1 discharge, the larger of the two discharge data sets, differences were statistically significant for total zooplankton at all three incubation times. These mean mortality differences were small, averaging less than $2.2 \%$. Intake-discharge differences in mortality were most strongly associated with calanoid copepods, especially immature and adult Diaptomus species,

Table 2. Mean mortalities over the $1975-1982$ period in the 0 -h incubation samples calculated as weighed means $\left(\bar{x}_{w}\right)$ for 29 zooplankton taxa in intake and discharge samples. $n$ is the number of months represented. Mean percent composition values are presented as weighed means (\% Comp)

\begin{tabular}{|c|c|c|c|c|c|c|c|}
\hline \multirow[b]{2}{*}{ Taxon } & \multicolumn{2}{|c|}{ Intake } & \multicolumn{2}{|c|}{ Discharge 1} & \multicolumn{2}{|c|}{ Discharge 2} & \multirow[b]{2}{*}{$\%$ Comp. } \\
\hline & $\bar{x}_{w}$ & $n$ & $\bar{x}_{w}$ & $n$ & $\bar{x}_{*}$ & $n$ & \\
\hline Copepod nauplii & 14.02 & 85 & 13.25 & 73 & 17.68 & 39 & 13.03 \\
\hline Cyclops spp Cl-C5 & 09.38 & 85 & 10.29 & 72 & 12.96 & 39 & 17.20 \\
\hline Cyclops bicuspidatus thomasi $\mathrm{C} 6$ & 06.49 & 81 & 08.09 & 66 & 11.72 & 38 & 02.98 \\
\hline Cyclops vernalis $\mathbf{C} 6$ & 05.07 & 31 & 03.36 & 26 & 03.03 & 14 & 00.17 \\
\hline Tropocyclops $\mathrm{C} 1-\mathrm{C} 5$ & 19.54 & 25 & 11.21 & 25 & 15.38 & 9 & 00.12 \\
\hline Tropocyclops prasinus mexicanus $\mathrm{C} 6$ & 05.47 & 51 & 05.61 & 47 & 04.97 & 17 & 01.57 \\
\hline Diaptomus spp $\mathrm{Cl}-\mathrm{C} 5$ & 17.11 & 85 & 22.70 & 73 & 27.23 & 39 & 08.73 \\
\hline Diaptomus ashlandi $\mathrm{C} 6$ & 08.31 & 75 & 09.08 & 56 & 10.72 & 31 & 06.14 \\
\hline Diaptomus minutus C6 & 05.42 & 76 & 11.85 & 65 & 09.23 & 35 & 01.75 \\
\hline Diaptomus oregonensis $\mathrm{C} 6$ & 06.18 & 46 & 07.57 & 47 & 09.52 & 22 & 01.99 \\
\hline Diaptomus sicilis $\mathrm{C} 6$ & 04.62 & 49 & 07.31 & 44 & 04.75 & 25 & 02.13 \\
\hline Epischura $\mathrm{Cl}-\mathrm{Cs}$ & 29.57 & 39 & 31.84 & 33 & 27.96 & 18 & 00.46 \\
\hline Epischura lacustris $\mathrm{C6}$ & 26.19 & 18 & 21.21 & 18 & 11.54 & 8 & 00.05 \\
\hline Eurytemora $\mathrm{Cl}-\mathrm{C} 5$ & 08.81 & 47 & 10.28 & 39 & 11.63 & 22 & 01.21 \\
\hline Eurytemora affinis $\mathrm{C6}$ & 16.67 & 31 & 10.53 & 26 & 14.81 & 8 & 00.15 \\
\hline Limnocalanus $\mathrm{Cl}-\mathrm{C} 5$ & 35.31 & 23 & 42.62 & 24 & 50.92 & 13 & 00.50 \\
\hline Limnocalanus macrurus $\mathrm{C} 6$ & 06.64 & 32 & 13.55 & 27 & 25.90 & 19 & 01.96 \\
\hline Bosmina longirostris & 08.71 & 69 & 08.49 & 62 & 08.85 & 30 & 28.98 \\
\hline Ceriodaphnia quadrangula & 04.44 & 8 & 17.54 & 9 & 09.23 & 6 & 00.09 \\
\hline Chydorus sphaericus & 03.30 & 32 & 02.32 & 28 & 03.02 & 17 & 00.58 \\
\hline Daphnia galeata mendotae & 14.18 & 41 & 17.24 & 38 & 11.24 & 21 & 00.54 \\
\hline Daphnia retrocurva & 17.41 & 47 & 18.36 & 44 & 12.64 & 23 & 02.41 \\
\hline Diaphanosoma leuchtenbergianum & 46.34 & 18 & 40.36 & 20 & 14.29 & 4 & 00.16 \\
\hline Eubosmina coregoni & 06.94 & 50 & 07.40 & 49 & 12.80 & 23 & 05.33 \\
\hline Holopedium gibberum & 36.92 & 20 & 37.78 & 17 & 53.33 & 5 & 00.09 \\
\hline Leptodora kindtii & 26.47 & 13 & 41.86 & 12 & 40.00 & 2 & 00.04 \\
\hline Polyphemus pediculus & 30.56 & 12 & 13.33 & 9 & 30.77 & 4 & 00.04 \\
\hline Asplanchna spp & 06.05 & 46 & 04.15 & 44 & 09.93 & 21 & 01.28 \\
\hline Total zooplankton & 10.23 & 85 & 11.37 & 73 & 13.41 & 39 & \\
\hline
\end{tabular}




\begin{tabular}{|c|c|c|c|c|}
\hline Incubation & Taxon & $n$ & $P$ & $\begin{array}{c}\bar{d} \\
(\%)\end{array}$ \\
\hline 0 -h & $\begin{array}{l}\quad \text { Discharge } \\
\text { Diaptomus spp C1-C5 } \\
\text { Diaptomus minutus } \mathrm{C} 6 \\
\text { Eurytemora affinis } \mathrm{Cl}-\mathrm{C} 5 \\
\text { Limnocalanus macrurus } \mathrm{C} 6 \\
\text { Daphnia retrocurva }\end{array}$ & $\begin{array}{l}53 \\
27 \\
17 \\
11 \\
20\end{array}$ & $\begin{array}{r}<0.001 \\
0.021 \\
0.039 \\
<0.009 \\
0.040\end{array}$ & $\begin{array}{l}9.56 \\
4.61 \\
1.74 \\
8.57 \\
5.16\end{array}$ \\
\hline 6-h & $\begin{array}{l}\text { Diaptomus spp C1-C5 } \\
\text { Diaptomus minutus } \mathrm{C} 6 \\
\text { Diaptomus oregonensis } \mathrm{C6} 6 \\
\text { Limnocalanus macrurus } \mathrm{C} 6 \\
\text { Daphnia galeata } \\
\text { Eubosmina coregoni }\end{array}$ & $\begin{array}{l}53 \\
21 \\
14 \\
11 \\
12 \\
19\end{array}$ & $\begin{array}{r}<0.001 \\
0.003 \\
0.025 \\
<0.016 \\
<0.017 \\
0.016\end{array}$ & $\begin{array}{l}6.27 \\
6.53 \\
3.03 \\
3.82 \\
6.82 \\
4.51\end{array}$ \\
\hline 24-h & $\begin{array}{l}\text { Diaptomus spp } \mathrm{Cl}-\mathrm{C} 5 \\
\text { Diaptomus ashlandi } \mathrm{C} 6 \\
\text { Diaptomus minutus } \mathrm{C6}\end{array}$ & $\begin{array}{l}50 \\
32 \\
21\end{array}$ & $\begin{array}{l}0.001 \\
0.050 \\
0.050\end{array}$ & $\begin{array}{l}6.41 \\
1.96 \\
3.96\end{array}$ \\
\hline 0 -h & $\begin{array}{l}\text { Discharge } \\
\text { Diaptomus spp C1-C5 } \\
\text { Total zooplankton }\end{array}$ & $\begin{array}{l}23 \\
26\end{array}$ & $\begin{array}{l}0.005 \\
0.043\end{array}$ & $\begin{array}{l}8.99 \\
2.49\end{array}$ \\
\hline 24-h & $\begin{array}{l}\text { Diaptomus spp C1-C5 } \\
\text { Total zooplankton }\end{array}$ & $\begin{array}{l}19 \\
26\end{array}$ & $\begin{array}{l}0.016 \\
0.033\end{array}$ & $\begin{array}{l}5.36 \\
2.06\end{array}$ \\
\hline
\end{tabular}

Eurytemora affinis and Limnocalanus macrurus. However, these mean mortality differences were not strongly related to animal size with immature $D i$ aptomus spp copepodites having the greatest mean differential mortality. Cyclopoid copepods were less vulnerable to plant passage; no statistically significant differences were detected for Unit 1 data. Among the Cladocera, significant differences were detected only for Daphnia species and Eubosmina coregoni for Unit 1 discharge. Although Bosmina longirostris was the most abundant cladoceran, intake and discharge mortalities for this species were not significantly different. The Unit 2 discharge data set was smaller because this unit was operational for a shorter period of time than Unit 1. Significant differences were detected only for total zooplankton and for immature Diaptomus species. Overall, mortality differences did not increase with incubation period for either discharge location. Furthermore, there was no evidence that zooplankton mortalities were substantially different between the two units.

The above analyses were repeated at coarser taxonomic levels, i.e. at the genus and suborder levels. Taxonomic data were combined to increase sample size, possibly allowing for the detection of an increased number of mortality differences. It further tested for differential sensitivity to plant passage for a broader class of organisms. For Unit 1 discharge (Table 4), results were similar to those conducted using finer levels of taxonomic identification. Calanoid copepods, especially Diaptomus species, were especially sensitive to plant passage. Mortality differences were smaller and less consistent for cyclopoid copepods and for cladocerans (Daphnia species). Similar results were obtained for the Unit 2 discharge comparisons. Overall, there were no large differences in zooplankton mortalities between Unit 1 and Unit 2 discharge samples.

\section{DISCUSSION}

Our results suggest that plant passage is lethal to a small percentage of zooplankton which pass through the condenser cooling system of the Donald C. Cook Nuclear Plant. The mean 0-h mortality difference for total zooplankton in Unit 1 and Unit 2 discharges averaged $<3 \%$. These relatively small mean mortality differences are similar to those observed at other power plants on Lake Michigan (Industrial Bio-Test Laboratories, 1974a; Wetzel, 1975; Limnetics, 1975, 1976). Furthermore, there was no evidence that delayed mortality effects were significant, either over a 24-hour period (this paper) or over a period of weeks (Evans et al., 1978). Similarly, Davies et al. (1976) did not observe a significant long-term (2 weeks) increase in zooplankton mortalities after plant passage.

There was strong evidence that calanoid copepods were most sensitive to plant passage. Diaptomus, Eurytemora and Limnocalanus all had significantly higher discharge water than intake water mortalities. Cladocerans were intermediate in sensitivity to plant passage with Eubosmina coregoni and Daphnia, the most sensitive taxa within this group. In contrast, cyclopoid copepods were relatively resistant to damage inflicted as a result of plant passage. Similar differential sensitivity among zooplankton taxa to plant passage has been observed in other studies (Davies and Jensen, 1974; Wetzel, 1975; Schubel et al., 1978). Comparative laboratory studies have 
Table 4. Major zooplankton categories for which discharge mortalities were significantly higher than intake mortalities over the 1975-1982 period as determined by the Wilcoxon sign-rank test. $n$ is the number of monthly pairs of values examined, $P$ is the attained level of significance, and $\bar{d}$ is the mean monthly difference in mortalities, discharge minus intake

\begin{tabular}{|c|c|c|c|c|}
\hline \multicolumn{5}{|c|}{ Major zooplankton category results } \\
\hline Incubation & Taxon & $n$ & $P$ & $\begin{array}{c}\bar{d} \\
(\%)\end{array}$ \\
\hline \multicolumn{5}{|c|}{ Discharge Unit 1} \\
\hline $0-\mathbf{h}$ & Calanoids $\mathrm{Cl}-\mathrm{C} 6$ & 60 & $<0.001$ & 6.02 \\
\hline & Calanoids $\mathrm{Cl}-\mathrm{C} 5$ & 60 & 0.001 & 6.00 \\
\hline & Diaptomus spp $\mathrm{Cl} 1-\mathrm{C} 6$ & 60 & $<0.001$ & 6.69 \\
\hline & Diaptomus spp C6 & 55 & 0.029 & 4.02 \\
\hline & Total zooplankton & 60 & 0.005 & 1.56 \\
\hline \multirow[t]{5}{*}{$6-h$} & Calanoids $\mathrm{C} 1-\mathrm{C} 6$ & 59 & $<0.001$ & 5.81 \\
\hline & Calanoids $\mathrm{C} 1-\mathrm{C} 5$ & 59 & $<0.001$ & 6.66 \\
\hline & Diaptomus spp $\mathrm{Cl}-\mathrm{C} 6$ & 59 & $<0.001$ & 5.47 \\
\hline & Diaptomus spp C6 & 55 & 0.016 & 3.06 \\
\hline & Total zooplankton & 59 & $<0.001$ & 2.13 \\
\hline \multirow[t]{6}{*}{ 24-h } & Cyclopoids $\mathrm{Cl}-\mathrm{C} 6$ & 60 & 0.015 & 1.75 \\
\hline & Calanoids C1-C6 & 60 & 0.002 & 5.12 \\
\hline & Calanoids $\mathrm{C} 1-\mathrm{C} 5$ & 60 & 0.003 & 5.85 \\
\hline & Diaptomus spp $\mathrm{Cl}-\mathrm{C} 6$ & 60 & 0.001 & 5.16 \\
\hline & Daphnia spp & 41 & 0.041 & 3.37 \\
\hline & Total zooplankton & 60 & 0.023 & 1.87 \\
\hline \multicolumn{5}{|c|}{ Discharge Unit 2} \\
\hline \multirow[t]{3}{*}{$0-h$} & Calanoids $\mathrm{Cl}-\mathrm{C} 6$ & 26 & 0.006 & 6.00 \\
\hline & Calanoids C1-C5 & 26 & 0.004 & 8.77 \\
\hline & Diaptomus spp C1-C6 & 26 & 0.005 & 6.06 \\
\hline \multirow[t]{3}{*}{ 24-h } & Cyclopoids C1-C6 & 26 & 0.016 & 2.90 \\
\hline & Calanoids $\mathrm{Cl}-\mathrm{C} 6$ & 26 & 0.019 & 3.76 \\
\hline & Diaptomus spp C1-C6 & 26 & 0.031 & 3.86 \\
\hline
\end{tabular}

shown that the cyclopoid Cyclops bicuspidatus thomasi has broader thermal tolerances than the calanoid Diaptomus spp, (Industrial Bio-Test Laboratories, 1974b). Furthermore, C. bicuspidatus thomasi is more tolerant of high concentrations of chlorine than Limnocalanus macrurus, another calanoid copepod (Latimer et al., 1971). Overall, cyclopoids may be more robust animals than calanoids and may have greater tolerances to physical and chemical environmental stresses, including those which are encountered during plant passage.

At the Donald C. Cook Nuclear Plant, zooplankton mortalities were a result of thermal and/or mechanical stresses. Biocides were not a significant source of mortality. The power plant infrequently chlorinated cooling waters to control biofouling until 1978 when treatment was discontinued. As chlorination was infrequent, mortality studies did not coincide with biocide application. Entrained sand, which provided sufficient scouring action to negate the use of biocides, may also have contributed to the mechanical stresses (abrasion, collision) experienced by zooplankton passing through the plant (Marcy et al., 1978).

There was little evidence that thermal stresses were the major cause of zooplankton mortality at the Donald C. Cook Nuclear Plant. Two sets of evidence, in the form of previous studies on zooplankton thermal tolerances and the relationship between zooplankton mortalities and thermal regime, suggest that the power plant generally operated within the thermal tolerance ranges of Lake Michigan zooplankton.
Mortalities did not increase in summer when discharge water temperatures were highest and zooplankton most likely to experience thermal regimes at (or above) their upper critical thermal limit. The single exception to this statement, September 1978, will be discussed later. Nor did zooplankton mortalities increase in winter when cold-adapted species were prevalent.

Mortalities in discharge water were not significantly correlated with $\Delta T$ (Evans et al., 1982). Since $\Delta T$ showed little seasonal variation, this was not unexpected. Nor were differences between discharge and intake mortalities significantly correlated with discharge water temperature (Evans et al., 1982). We conclude that the moderate thermal elevations $\left(\Delta T<12^{\circ} \mathrm{C}\right)$ and short-term (min) exposures to discharge water temperatures below $35^{\circ} \mathrm{C}$ were not the major source of stress to zooplankton which passed through the condenser cooling system of the Donald C. Cook Nuclear Plant.

Results of previous field and laboratory studies support this conclusion. Short-term exposures to moderate thermal elevations do not become stressful to most zooplankton until a critical upper temperature is reached. For many organisms, this temperature is in the $30^{\prime} \mathrm{s}^{\circ} \mathrm{C}$ (Drost-Hansen, 1969) although latitudinal variations in tolerance occur (Brown, 1929). Moreover, thermal tolerance varies with acclimation temperature (Heinle, 1969; Schubel et al., 1978). Diaptomus spp copepodites reared at $1^{\circ} \mathrm{C}$ have a median lethal temperature of $32.6^{\circ} \mathrm{C}$ (2-min exposure, $\Delta T$ of $31.6^{\circ} \mathrm{C}$ ) whereas animals 
reared at $20^{\circ} \mathrm{C}$ have a median lethal temperature of $34.5^{\circ} \mathrm{C}$ (2-min exposure; $\Delta T$ of $14.5^{\circ} \mathrm{C}$ ) (Industrial Bio-Test Laboratories, 1974b). Furthermore, Cyclops spp copepodites are more tolerant of elevated temperatures than Diaptomus spp copepodites (Industrial Bio-Tech Laboratories, 1974b).

One important aspect of thermal tolerance is the sharp decrease in survivorship which may occur as water temperatures are increased by as little as a 1-2 ${ }^{\circ} \mathrm{C}$. Brown and Crozier (1927-1928) observed that Daphnia pulex will live and reproduce near $30^{\circ} \mathrm{C}$ but will die at $32^{\circ} \mathrm{C}$; thus a sharp transition in survivorship occurred near $31^{\circ} \mathrm{C}$. Therefore, a power plant may inflict minimal mortalities on zooplankton by operating at discharge water temperatures 2 or $3^{\circ} \mathrm{C}$ below the upper critical temperature. However, a slight increase in temperature may result in a dramatic increase in zooplankton mortalities. Such an increase apparently was observed at the Donald C. Cook Nuclear Plant in September 1978 when discharge water temperatures slightly exceeded $35^{\circ} \mathrm{C}$ and 0 -h net mortalities were $14 \%$ for Unit 2 (discharge water temperature $35.2^{\circ} \mathrm{C}$ ) and $22 \%$ for Unit 1 (discharge water temperature $35.6^{\circ} \mathrm{C}$ ). Other studies have shown that when discharge water temperatures reach $40^{\circ} \mathrm{C}$, mortalities may exceed $80 \%$ (Reeve, 1970; Brauer et al., 1974).

Mechanical stresses probably were the major source of zooplankton mortality at the Donald $C$. Cook Nuclear Plant. Some zooplankton clearly were physically damaged by plant passage (and by the collection process). Antennae and urosomes were torn, carapaces bent backwards, and the body wall ruptured. Studies conducted at the Nanticoke Generating Station showed clear quantitative evidence that zooplankton were physically damaged by plant passage although mortalities were not determined (Standke and Munroe, 1981). Other studies have implicated mechanical stresses as the significant source of mortality both to zooplankton (Carpenter et al., 1974; Marcy et al., 1978) and fish (Marcy, 1973) at power plants where organisms are exposed to moderate thermal elevations for short periods of time.

Factors causing mechanical stress are poorly understood. While some researchers have suggested that mortalities are a linear function of zooplankton size (Wetzel, 1975), the relationship probably is best described by a second- or third-order function. We observed that, for small $(<1.5 \mathrm{~mm}$ ) zooplankton, mortalities were not size related. For such taxa, mortalities appear to be a function of inherent taxonomic sensitivies, i.e. calanoids were relatively more sensitive to plant passage than cyclopoid copepods. However, as zooplankton size increases $(>1.5 \mathrm{~mm}$ ), the mortality-size relationship may become stronger. Other studies have suggested that larger zooplankton are more vulnerable to plant passage than smaller zooplankton (Schubel et al., 1978).

Power plants are highly variable in their mode of operation $(\Delta T$, discharge water temperature, pumping rate, flow-through rate, use of biocides, etc.). Comparative studies conducted by the same researchers using the same methods have shown that plant operating characteristics have a significant effect on zooplankton mortalities; rates generally are highest for plants with the greatest $\Delta T$ and where discharge water temperatures reach the mid-30's ${ }^{\circ} \mathrm{C}$ (Davies and Jensen, 1974; Icanberry and Adams, 1974). At the Donald C. Cook Nuclear Plant, where the $\Delta T$ $\left(<12^{\circ} \mathrm{C}\right)$ is moderate and discharge water temperatures generally do not exceed $35^{\circ} \mathrm{C}$, zooplankton mortalities as a result of plant passage are low $(<3 \%)$.

The numerical loss of zooplankton resulting from passage through the Donald C. Cook Nuclear Plant is a function of the mean percentage mortality of zooplankton in Units 1 and 2 cooling waters, the volumetric concentration of zooplankton in these waters, and the total volume flow for each unit. There were no substantial differences in the mean percentage mortality (or concentration) or zooplankton in the cooling waters of Units 1 and 2 . However, because Unit 2 utilized approx. 34\% more water than Unit 1, more zooplankton were killed passing through Unit 2 over a given interval of time than Unit 1. Our data suggest that, were Unit 2 originally designed to operate under the same conditions as Unit 1 (i.e. at a lower flow rate but a somewhat higher $\Delta T)$, the plant would use approx. $15 \%$ less water $\{[(3979-2964) \times 100] /(3979+2964)\}$ and the daily loss rate of zooplankton would decrease by approx. 15\%. Schubel et al. (1978) suggest that this low volume concept is most effective in reducing the adverse effects of plant operation when physical stresses are the major source of mortality.

Preoperational (1970-1974) studies were conducted to determine zooplankton population dynamics and spatial patterns prior to plant operation. During much of the year, there were large inshore-offshore gradients in zooplankton community structure (Evans, 1975). These gradients continued to persist during the operational (1975-1982) period (Evans et al., 1980, 1986). The major feature of these gradients was the dominance of the inshore zooplankton community by small-bodied taxa while larger taxa became more abundant in offshore waters (Hawkins and Evans, 1979; Evans et al., 1980). We hypothesized that inshore-offshore gradients in fish planktivores had a significant role in shaping inshoreoffshore gradients in zooplankton community structure.

The inshore region serves as an important nursery ground for many species of fish including the alewife (Alosa pseudeoharengus), yellow perch (Perca flavescens) and smelt (Osmerus mordax) (Wells, 1968). The early life history stages of these fish are planktivorous while adult smelt and yellow perch are facultative planktivores: alewives remain planktivorous as adults (Scott and Crossman, 1973). 
Planktivores exert size-selective predation pressures on the zooplankton community, altering zooplankton community structure towards a greater dominance by small species (Brooks and Dodson, 1965; Zaret, 1980). Thus, we hypothesized that the dominance of the inshore region zooplankton community by small-bodied species was a consequence of the high concentrations of fish planktivores in this region (Evans et al., 1980). This implies that fish predation was a major factor affecting zooplankton mortality in the inshore region, especially for largebodied species.

Our long-term (1970-1982) ecological studies suggest that power plant operation was not a significant factor affecting zooplankton survivorship in the inshore region. We were unable to detect any temporal or spatial alterations in zooplankton community structure in the vicinity of the plant which could be attributable to plant-induced mortality (Evans, 1981; Evans et al., 1982, 1986); only minor effects were detected for the epibenthic and benthic microcrustacean communities (Evans, 1984). This inability to detect any losses due to plant operation is readily understood when consideration is given to the percentage mortality of zooplankton in the cooling waters, the mixing characteristics of the thermal plume, and the inherent variability of zooplankton populations. Since the power plant utilizes subsurface discharge jets, heated water is rapidly cooled through dilution. The water column immediately over the discharge jets contains, on average, a mixture of $30 \%$ condenser-passed and $70 \%$ plume-entrained waters. Assuming that the average mortality of zooplankton passing through the plant is $3 \%,<1 \%$ of the zooplankton sampled over the discharge jets are dead as a direct result of plant passage. As the thermal plume moves out into the lake and is further diluted, this percentage rapidly decreases. These small decreases in zooplankton abundances are below detection limits (Evans and Sell, 1983). Thus, the spatial and temporal characteristics of zooplankton populations remained similar during the preoperational and much of the operational period. Although some changes were detected in zooplankton community structure between the preoperational and operational periods, these changes occurred both in the plume and control regions and thus could not be attributed to plant operation (Evans et al., 1986). Furthermore, these changes magnified in the late 1970s and early 1980 s as other known environmental pertubations to the lake increased in amplitude.

Lake Michigan has been exposed to many environmental perturbations in addition to thermal pollution, i.e. eutrophication, overfishing, and the invasion of exotics such as the alewife (Alosa pseduoharengus) (Beeton, 1969; Christie, 1974). In areas where eutrophication has been minimal (including southeastern Lake Michigan), the alewife has had a strong effect on the zooplankton community (Wells, 1970). Temporal changes in alewife populations have been fol- lowed by changes in zooplankton community structure (Brooks and Dodson, 1965; Wells, 1970). Furthermore, alewife predation may affect spatial gradients in zooplankton community structure (Evans et al., 1980).

In the late 1970s the early 1980s, alewife populations declined markedly in Lake Michigan waters. Concurrent with this was an increase in yellow perch populations in the inshore region and bloaters (Core gonus hoyi) in the offshore region (Jude and Tesar, 1985; Evans and Jude, 1986). As these changes occurred, there were major alterations in zooplankton community structure with the nature of these changes differing between the inshore and offshore regions as a function of spatial differences in the abundances of the various fish planktivores. In the inshore region, Daphnia spp abundances declined markedly over summer and autumn 1982-1984, averaging only $10 \%$ of their $1972-1981$ abundances. This decrease was attributed to the strong increase in yellow perch abundances (Evans and Jude, 1986). Furthermore, total summer zooplankton standing stocks were depressed to $10 \%$ of their earlier values (Evans, 1986). Thus, the only long-term changes which we were able to detect in zooplankton populations in the inshore region over the 1975-1982 operational period (and small studies conducted in 1983 and 1984) were those attributable to changes in the fish community.

In summary, our long-term studies have shown that a small percentage of zooplankton are killed as a result of passage through the condenser cooling system of the Donald C. Cook Nuclear Plant. Such small losses cannot be detected in the lake. Our long-term ecological studies suggest that the fish predation rather than power plant operation is the greater source of mortality to zooplankton inhabiting the inshore region during much of the year.

Acknowledgements - This research was supported by the Indiana \& Michigan Electric Co. Special thanks are extended to $J$. Ayers for his support and encouragement through the study and to the many zooplankton personnel who participated in this most demanding aspect of our field program. Reviewers were D. Jude and E. Stoermer. Contribution No. 441. Great Lakes Research Division.

\section{REFERENCES}

Beeton A. M. (1969) Changes in the environment and biota of the Great Lake In Eutrophication: Causes, Consequences, Correctives, pp. 150-187. National Academy of Sciences.

Brauer G. A., Neill W. M. and Magnuson J. J. (1974) Effects of a power plant on zooplankton distribution and abundance near plant's effluent. Wat. Res. 8, 485-489.

Brooks J. L. and Dodson S. I. (1965) Predation, body size and composition of plankton. Science 150, 28-35.

Brown L. A. (1929) The natural history of cladocerans in relation to temperature-I. Distribution and the temperature limits for vital activities. Am. Nat. 68, 248-264.

Brown L. A. and Crozier W. J. (1927-1928) The rate of killing of cladocerans at higher temperatures. $J$. gen. Physiol. 11, 25-36.

Carpenter E. J., Peck B. B. and Anderson S. J. (1974) Survival of copepods passing through a nuclear power 
station on northwestern Long Island Sound, U.S.A. Mar. Biol. 24, 49-55.

Christie W. J. (1974) Changes in the fish species composition of the Great Lakes. J. Fish Res. Bd Can. 31, 827-854.

Cochran W. G. (1977) Sampling Techniques. Wiley, New York.

Conover W. J. (1980) Practical Nonparametric Statistics, 2nd edition. Wiley, New York.

Davies R. M. and Jensen L. M. (1974) Zooplankton entrainment at three mid-Atlantic power plants. $J$. Wat. Pollut. Control Fed. 47, 2130-2142.

Davies R. M., Hanson C. H. and Jensen L. D. (1976) Entrainment of estuarine zooplankton in a mid-Atlantic power plant: delayed effects. In Thermal Ecology II (Edited by Esch G. W. and McFarlane R. W.), pp. 348-357. Technical Information Center, Energy Research Development Center.

Drost-Hansen W. (1969) Allowable thermal pollution limits-a physiochemical approach. Chesapeake Sci. 10, 281-288.

Edmondson W. T. (1959) Fresh-Water Biology, 2nd edition. Wiley, New York.

Evans M. S. (1975) The 1974 preoperational zooplankton investigations relative to the Donald $\mathrm{C}$. Cook nuclear plant. University of Michigan, Great Lakes Research Division, Special Report No. 58.

Evans M. S. (1981) Distribution of zooplankton populations within and adjacent to a thermal plume. Can. $J$. Fish. Aquat. Sci. 38, 441-448.

Evans M. S. (1984) Benthic and epibenthic (microcrustaceans, macrobenthos) community structure in the vicinity of a power plant, southeastern Lake Michigan. Verh. int. Verein. Limnol. 22, 488-494.

Evans M. S. (1986) Recent declines in zooplankton populations in the inshore region of Lake Michigan: probable causes and consequences. Can. J. Fish. Aquat. Sci. In press.

Evans M. S. and Jude D. J. (1986) Recent shifts in Daphnia community structure in southeastern Lake Michigan: a comparison of the inshore and offshore regions. Limnol. Oceanogr. In press.

Evans M. S. and Sell D. W. (1983) Zooplankton sampling strategies for environmental studies. Hydrobiologia 99, 215-223.

Evans M. S., Hawkins B. E. and Sell D. W. (1980) Seasonal features of zooplankton assemblages in the nearshore area of southeastern Lake Michigan. J. Great Lakes Res. 6, 275-289.

Evans M. S., Sell D. W. and Page D. I. (1982) Zooplankton studies in 1977 and 1978 at the Donald C. Cook Nuclear Power Plant: comparisons of preoperational (1971-1974) and operation (1975-1978) population characteristics. University of Michigan, Great Lakes Research Division, Special Report No. 89.

Evans M. S., Wurster T. E. and Hawkins B. E. (1978) The 1975 and 1976 operational zooplankton investigations relative to the Donald C. Cook Nuclear Power Plant, with tests for plant effects (1971-1976). University of Michigan, Great Lakes Research Division, Special Report No. 58.

Evans M. S., Warren G. J., Page D. I. and Flath L. F. (1986) Zooplankton studies at the Donald C. Cook Nuclear Power Plant: 1979-1982 investigations including preoperational (1971-1974) and operational (1975-1982) comparisons. University of Michigan, Great Lakes Research Division, Special Report No. 111.

Haney J. F. and Hall D. J. (1973) Sugar-coated Daphnia: a preservation technique for Cladocera. Limnol. Oceanogr. 18, 331-333

Hawkins B. E. and Evans M. S. (1979) Seasonal cycles of zooplankton biomass in southeastern Lake Michigan. J. Great Lakes Res. 5, 256-263.

Heinle D. R. (1969) Temperature and zooplankton. Chesapeake Sci. 10, 186-209.
Icanberry J. W. and Adams J. R. (1974) Zooplankton survival in cooling water systems for four thermal power plants on the California coast. In Proceedings of the $2 n d$ Workshop on Entrainment and Intake Screening (Edited by Jensen L. D.), pp. 13-22. Electric Power Research Institute, Palo Alto, Calif.

Industrial Bio-Test Laboratories Inc. (1974a) Environmental monitoring in Lake Michigan near Zion Station, July 1973-June 1974, Vol. 2. Report to Commonwealth Edison Co., Chicago, Ill.

Industrial Bio-Test Laboratories Inc. (1974b) Thermal tolerance limit determinations for Lake Michigan zooplankton. Project XVII-B IBT No. 643-01862, July 1972-March 1973. Report to Commonwealth Edison Co., Chicago, Ill.

Jude D. J. and Tesar F. J. (1985) Recent changes in the inshore forage fish of Lake Michigan. Can. J. Fish. Aquat. Sci. 42, 1154-1157.

Latimer D. L., Brooks A. S. and Beeton A. M. (1971) Toxicity of 30 minute exposures of residual chlorine to the copepods Limnocalanus macrurus and Cyclops bicuspidatus thomasi. J. Fish. Res. Bd Can. 32, 2495-2501.

Limnetics Inc. (1975) An environmental study of the ecological effects of thermal discharge from the Point Beach Nuclear Plant, November 1973-October 1974. Annual Report No. 2, Vol. 2. Report to the Wisconsin Power Co. and the Wisconsin Michigan Power Co.

Limnetics Inc. (1976) An environmental study of the ecological effects of thermal discharge from the Point Beach Nuclear Plant. November 1974-October 1975. Annual Report No. 3. Report to the Wisconsin Power Co. and Wisconsin Michigan Power Co.

Marcy B. C. (1973) Vulnerability and survival of young Connecticut River fish entrained at a nuclear power plant. J. Fish. Res. Bd Can. 30, 1195-1203.

Marcy B. C. Jr, Beck A. D. and Ulanowicz R. E. (1978) Effects and impacts of physical stress on entrained organisms. In Power Plant Entrainment. A Biological Assessment (Edited by Schubel J. R. and Marcy B. C. Jr), pp. 135-188. Academic Press, New York.

Raj D. (1968) Sampling Theory. McGraw-Hill, New York.

Reeve M. R. (1970) Seasonal changes in the zooplankton of south Biscayne Bay and some problems of assessing the effects on the zooplankton of natural and artificial thermal and other fluctuations. Bull. Mar. Sci. 20, 894-921.

Schubel J. R., Coutant C. C. and Woodhead P. M. J. (1978) Thermal effects of entrainment. In Power Plant Entrainment. A Biological Assessment (Edited by Schubel J. R. and Marcy B. C. Jr), pp. 19-99. Academic Press, New York.

Scott W. B. and Crossman E. J. (1973) Freshwater fishes of Canada. Fish Res. Bd Can. Bull. 184

Standke S. J. and Munroe B. P. (1981) Forms of physical damage and related effects to zooplankton as a result of entrainment at Nanticoke G. S., 1976. J. Great Lakes. Res. 7, 136-143.

Wells L. (1968) Seasonal depth distribution of fish in southeastern Lake Michigan. Fish. Bull. 67, 1-15.

Wells L. (1970) Effects of alewife predation on zooplankton populations in Lake Michigan. Limnol. Oceanogr. 15, 556-565.

Wetzel D. L. (1975) Zooplankton entrainment. Industrial Bio-Test Laboratories, Inc. operational environmental monitoring program of Lake Michigan near Kewaunee nuclear power plant: chemical and biological studies, Fourth annual report, January-December 1974. Report to Wisconsin Public Service Corp., Wisconsin Power and Light Co. and Madison Gas and Electric Co.

Yocum W. L., Evans M. S. and Hawkins B. E. (1978) A comparison of pump sampling systems for collecting live zooplankton. Hydrobiologia 60, 199-202.

Zaret T. M. (1980) Predation and Freshwater Communities. University Press of New England, Hanover. 